LANA, MM. 2016. Estação de trabalho: infraestrutura para beneficiamento de hortaliças em pequenas propriedades rurais. Horticultura Brasileira 34: 443447. DOI - http://dx.doi.org/10.1590/S0102-05362016003023

\title{
Estação de trabalho: infraestrutura para beneficiamento de hortaliças em pequenas propriedades rurais
}

\author{
Milza M Lana \\ Embrapa Hortaliças, Brasília-DF, Brasil; milza.lana@embrapa.br
}

\begin{abstract}
RESUMO
O manuseio descuidado das hortaliças a partir da colheita contribui para o elevado volume de perdas deste grupo de alimentos. As perdas pós-colheita podem ser quantitativas, representadas pela fração do alimento que não é consumido mas descartado, ou qualitativas, quando se referem ao decréscimo da qualidade sensorial, nutricional e microbiológica do alimento ainda próprio para consumo. Com o objetivo de melhorar as condições de trabalho durante a colheita e beneficiamento de hortaliças em pequenas propriedades rurais, a Embrapa Hortaliças propôs a instalação de uma estação de trabalho de baixo custo, composta de três equipamentos: casa de embalagem de lona, carrinho para transporte e mesa para seleção. Estes equipamentos contribuem para preservar a qualidade da hortaliça colhida, por meio da redução dos estresses abióticos (calor, deposição de orvalho, chuva e danos físicos), e consequentemente, aumentam a sua durabilidade e o tempo disponível para a sua comercialização. Adicionalmente têm efeitos sobre a saúde do trabalhador rural e sobre o rendimento do trabalho. Os efeitos benéficos sobre a saúde do trabalhador incluem a redução do tempo de exposição ao sol e dos problemas osteo-musculares causados pelo carregamento de cargas pesadas e/ou distribuídas assimetricamente e por operações repetitivas e/ou posturas inadequadas. $\mathrm{O}$ aumento do rendimento do trabalho resulta da eliminação de etapas repetitivas, redução do cansaço causado pela sobrecarga do sistema músculo-esquelético, redução do desconforto térmico e pela possibilidade de execução do beneficiamento das hortaliças sob condições de chuva.
\end{abstract}

Palavras-chave: perdas pós-colheita, hortaliças, casa de embalagem, mesa de seleção, carrinho.

\begin{abstract}
Working station: infrastructure for vegetable harvesting and postharvest handling in small farms

The rough handling during harvest and preparation for the market contributes to the high volume of postharvest losses observed for vegetables. Postharvest losses of vegetables may be either in quantity, when food is not consumed but discarded, or in quality, when the sensory, nutritional or microbiological quality is reduced even when the food is suitable for consumption. In order to improve the infrastructure for harvest and post-harvest handling of vegetables in small farms, Embrapa Vegetables recommended a low cost working station made of three equipment: a tarp packing house; a wheelbarrow and a sorting table. These equipments contribute for the maintenance of the vegetable quality by reducing biotic and abiotic stresses (such as heat, dew, rain, mechanical damage) during harvest and postharvest handling and consequently extends the shelf life and the time available for the farmer to market his product. Additional benefits are related to the rural worker health and the working efficiency. Benefits for the worker health include the reduction of exposure to the sun and reduction of work-related musculoskeletal disorders caused by heavy loads, repetitive movements and/or awkward positions. Higher working efficiency is due to the elimination of repetitive activities, less tiredness due to overloading of the musculoskeletal system, reduction of thermal discomfort and the possibility to keep working when it is raining.
\end{abstract}

Keywords: Postharvest loss, vegetables, packing house, sorting table, wheelbarrow.

(Recebido para publicação em 19 de outubro de 2015; aceito em 7 de abril de 2016)

(Received on October 19, 2015; accepted on April 7, 2016)

\begin{abstract}
Volume e custo das perdas de alimentos

Aproximadamente $1 / 3$ de todo o alimento produzido no mundo para consumo humano é perdido ou desperdiçado, totalizando cerca de 1,3 bilhão de toneladas por ano segundo estimativas da FAO (FAO, 2011). O valor financeiro dessa perda foi estimado em US\$ 936 bilhões ao ano, valor este que não considera os custos ambientais e sociais (FAO, 2014).
\end{abstract}

Os custos sociais da perda de alimentos incluem os custos do alimento que não contribuiu para nutrir e mitigar a fome; do impacto de pesticidas na saúde humana; dos conflitos devido à pressão em recursos naturais e subsídios governamentais usados para produzir alimentos que vão para o lixo, dentre outros. Os custos ambientais por sua vez, incluem a perda de toda a energia e insumos utilizados na fase de produção (água, combustível, adubos, defensivos), distribuição (embalagens, transporte) e armazenamento. Adicionalmente, os alimentos depositados em aterros sanitários, ou simplesmente descartados no ambiente, produzem metano, um gás com efeito estufa 23 vezes mais potente do que o dióxido de carbono (WRAP, 2008; FAO, 2014; HLPE, 2014).

Além da redução na disponibilidade de alimentos, as perdas pós-colheita representam prejuízos ainda maiores à 
economia global quando se considera que, de maneira geral, a manutenção da quantidade e qualidade dos alimentos requer menos recursos e prejudica menos o ambiente do que o aumento de produção necessário para compensar estas perdas.

\section{Volume e causas de perdas de hortaliças}

O volume de perdas e desperdício de raízes e tubérculos (que inclui hortaliças como batata e batata doce) alcança de 30 a $60 \%$ da produção mundial, enquanto no grupo de frutas e hortaliças alcança entre 35 e $55 \%$ da produção, dependendo da região. $\mathrm{Na}$ América Latina estima-se que as perdas desses dois grupos de alimentos sejam particularmente importantes nas fases de produção (colheita) e pós-colheita, devido às condições de clima quente $\mathrm{e}$ úmido e manuseio inadequado durante a colheita, beneficiamento, transporte e comercialização (FAO, 2011). Esses dados devem ser considerados com bastante cautela, pois como alertam os próprios autores, eles foram calculados a partir de uma base de dados bastante estreita. Para regiões e/ou produtos para os quais não havia dados disponíveis, foram feitas estimativas e premissas com base nos dados de regiões, produtos ou elos da cadeia similares.

Avaliações de perdas de hortaliças no Brasil foram feitas de forma pontual e isolada por pesquisadores de diversas instituições (Zambom et al., 1991; Costa \& Rezende, 1992; Tsucheniro et al., 1994; SAASP, 1995; Caixeta Filho, 1996; Almeida \& Silva, 2008; Amorim et al., 2008). A utilização de metodologias distintas em cada um desses trabalhos dificulta a comparação dos valores obtidos, mas para diferentes produtos e elos da cadeia produtiva são reportadas perdas da ordem de 0 a $50 \%$ da massa de hortaliças. A quase totalidade dos trabalhos anteriores a 1995, incluindo uma série de levantamentos citados por Costa \& Caixeta Filho (1996), foram baseados em metodologia subjetiva, compreendendo principalmente a aplicação de questionários aos agentes de comercialização o que limitava em grande extensão a quantificação do volume e a identificação precisa das causas das perdas observadas. Em SAASP (1995) as perdas foram avaliadas por uma metodologia quantitativa e objetiva que incluía a definição da amostragem por métodos estatísticos próprios; aferição de massa, por balança, do produto segundo danos mecânicos, fisiológicos e patológicos. Almeida \& Silva (2008) por sua vez, utilizaram metodologia quantitativa para estimar as perdas de tomate na lavoura, no atacado e no varejo, mas não identificaram as causas específicas de perdas em cada elo da cadeia produtiva avaliada. Levantamentos mais recentes, que permitam estimar com precisão o volume de perdas em todo o país não são conhecidos pela autora. A despeito da escassez de dados recentes para as condições brasileiras e das mudanças ocorridas na comercialização de hortaliças do país nas últimas décadas comparativamente à época dos levantamentos citados (Farina, 2002), não seria incorreto afirmar que as perdas pós-colheita de hortaliças no Brasil são elevadas e em grande parte devidas ao precário manuseio pós-colheita em todos os elos da cadeia produtiva.

Estimativas de perdas pós-colheita pela Embrapa Hortaliças foram realizadas no Distrito Federal em dois momentos com metodologias distintas. No primeiro foram quantificadas as perdas de cenoura, tomate e pimentão em uma rede varejista, usando metodologia adaptada de SAASP (1995). Os volumes observados foram da ordem de $13 \%$, $30 \%$ e $20 \%$ da massa total para cenoura, tomate e pimentão, respectivamente (Vilela et al., 2003). As principais causas de perdas identificadas foram: dano mecânico e defeitos de formato para cenoura; dano mecânico e dano fisiológico para tomate; dano mecânico e doença fúngica e/ou bacteriana para pimentão.

Posteriormente, a avaliação qualitativa das perdas de hortaliças foi feita a partir da colheita até a expedição na casa de embalagem da cooperativa local (Lana, 2010; Lana et al., 2010; Lana \& Puerta, 2011). Na primeira etapa do estudo, foi mapeado o fluxo de trabalho que inclui todas as operações que interferem na qualidade das hortaliças, seguido pela análise das falhas em cada etapa do fluxo. Foram consideradas como falhas as operações e/ou os pro- cessos que podem acarretar um ou mais tipos de danos físicos e/ou biológicos que resultam em redução da qualidade das hortaliças (perda de valor nutricional, alteração prejudicial do sabor e textura, contaminação microbiológica) em perdas físicas (descarte do produto) e no envio de produtos não conformes aos clientes. Paralelamente aos trabalhos de mapeamento de processos e análise de falhas foi construída a ARA (árvore da realidade atual) por meio de entrevistas não estruturadas com pessoas de diferentes áreas e posições na estrutura organizacional, associadas à observação das operações e ao levantamento do histórico de problemas.

Este estudo resultou em um Plano de Ações de Melhoria relatando as necessidades de melhorias organizacionais e tecnológicas para mitigação das falhas identificadas. Uma das necessidades identificadas foi a melhoria da infraestrutura das propriedades para colheita e beneficiamento de hortaliças. Em relação ao manuseio pós-colheita das hortaliças propriamente dito, recomendou-se priorizar a simplificação dos fluxos de trabalho para reduzir o número de repasses a que são submetidos os produtos, com o objetivo de reduzir a incidência de danos mecânicos.

$\mathrm{Na}$ maioria dos estabelecimentos rurais avaliados, as operações de colheita e beneficiamento de hortaliças são realizadas em condições precárias, ocasionando danos ao produto hortícola e à saúde do trabalhador. As operações de beneficiamento (seleção, classificação, limpeza e embalagem) são, em geral, feitas ao ar livre, transferindo-se as hortaliças de um contentor para o outro, com o trabalhador em pé ou agachado. Algumas poucas propriedades contam com uma pequena área coberta de alvenaria onde a colheita é estocada até a expedição. Quando presentes, as mesas de seleção possuem a superfície áspera, são de difícil limpeza e higienização e apresentam altura não regulável, muitas vezes incompatível com a altura do trabalhador.

Estas condições de trabalho afetam negativamente o rendimento do trabalho, a saúde do trabalhador rural e a qualidade da hortaliça. Os principais danos causados às hortaliças nestas con- 


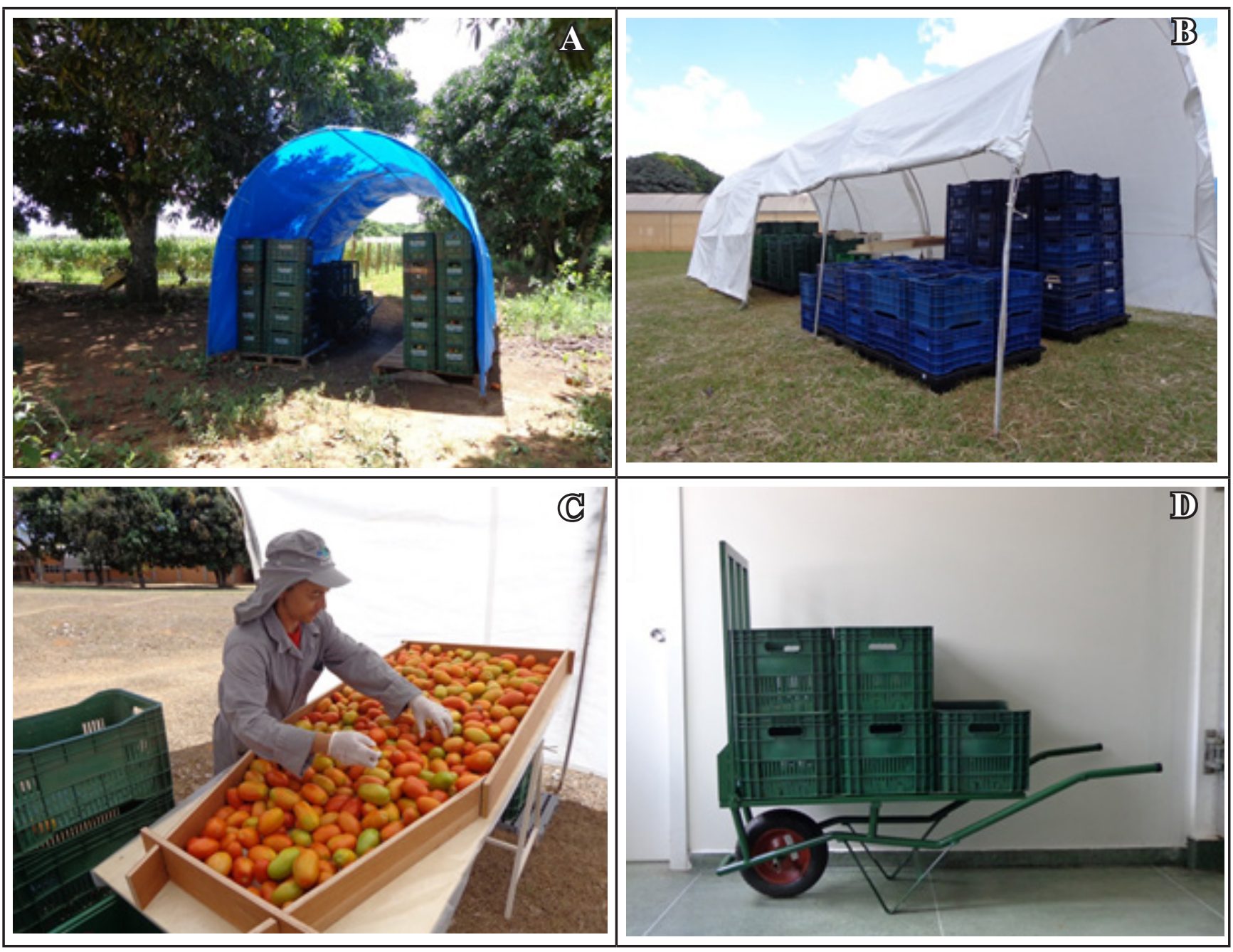

Figura 1. Componentes da estação de trabalho: unidade móvel de sombreamento (A); casa de embalagem de lona (B); mesa para seleção de hortaliças (C) e carrinho para transporte de hortaliças (D) \{working station components: shading mobile unit (A); tarp packing house (B); sorting table (C) wheelbarrow (D)\}. Brasília, Embrapa Hortaliças, 2014.

dições são a aceleração da senescência e da perda de água; o comprometimento da aparência do produto devido a sujidades e danos físicos; a contaminação do produto em contato com o solo ou com superfícies sujas ou contaminadas. Quanto à saúde do trabalhador, as principais doenças são aquelas causadas pela execução de operações repetitivas em posturas inadequadas e aquelas advindas da realização do trabalho ao ar livre, principalmente sob sol (Baron et al., 2001; BRASIL, 2001).

\section{Estação de trabalho para peque- nas propriedades rurais}

Tendo em vista os problemas relatados na sessão anterior, a Embrapa Hortaliças propôs a melhoria da infra-estrutura para colheita e beneficiamento de hortaliças em pequenas propriedades rurais através da instalação de três equipamentos que juntos formam uma estação de trabalho (Figura 1). Estes equipamentos compreendem:

1) Unidade móvel de sombreamento (UMS) ou casa de embalagem de lona. A UMS é uma estrutura metálica, composta de três arcos unidos na parte superior por uma barra por meio de parafusos. Os arcos são encaixados aos pés fixados no solo e cobertos por lona plástica amarrada à estrutura com corda. O módulo possui $4,85 \mathrm{~m}$ de comprimento por 3,5 m de largura e cerca de 2,4 metros de pé-direito na parte mais alta do arco. $\mathrm{O}$ tamanho da estrutura pode ser ajustado ao volume de produção através da anexação de módulos adicionais, formando uma casa de embalagem de lona. A estrutura é leve e móvel, o que permite a sua instalação próxima à lavoura, de modo que a hortaliça seja removida para a sombra imediatamente após a colheita. $O$ custo e o passo a passo para a construção e montagem do módulo unitário (UMS) e duplo são descritos respectivamente em Lana et al. (2014) e Lana (2014a).

2) Mesa para seleção de hortaliças. Possui tampo de compensado com paredes laterais que podem ser arranjadas para se obter uma mesa com cocho (depósito de contenção) ou com bica (calha para direcionar as hortaliças). O tampo deve ser coberto com filme de plástico para evitar danos físicos às hortaliças e facilitar a limpeza. Os pés da mesa são feitos de metalon e têm altura regulável, permitindo que o trabalhador ajuste a al- 
tura e a inclinação do tampo. Com o uso da mesa, a seleção das hortaliças é feita de maneira mais rápida e mais eficiente, pois o trabalhador consegue executar o trabalho em posturas mais confortáveis além de visualizar adequadamente os produtos a serem selecionados. O custo e o passo a passo para sua construção estão descritos em Lana (2014b).

3) Carrinho para colheita e transporte de hortaliças. Construído com metalon e tubo de ferro, o carrinho possui encosto dobrável e capacidade de até seis caixas de hortaliças. O mesmo carrinho pode ser usado durante a colheita, para o transporte das hortaliças da lavoura para a área sombreada e para o transporte de hortaliças no mercado. Ele permite a movimentação de cargas mais pesadas, comparativamente ao carregamento das caixas e baldes cheios, em postura menos danosa à musculatura e à coluna vertebral e diminui o número de vezes que o trabalhador precisa se abaixar e se levantar para carregar o contentor de colheita. O uso de carrinhos também evita que os contentores de colheita entrem em contato com o solo, facilitando sua manutenção e limpeza e aumentando sua durabilidade, além de evitar que as hortaliças se sujem em contato com o solo. O custo e o passo a passo para sua construção estão descrito em (Lana \& Batista, 2014).

4) Equipamentos adicionais: Por ser uma estrutura móvel construída próxima à lavoura, a UMS e a casa de embalagem de lona são montadas sob chão batido. Recomenda-se o uso de paletes de madeira ou de plástico, piso de plástico ou equivalente para evitar o contato das caixas de hortaliças com o solo.

$\mathrm{O}$ conjunto é adequado para pequenas propriedades rurais, onde não seja viável economicamente a construção de uma casa de embalagem de alvenaria e para meeiros e arrendatários que podem facilmente transportar os equipamentos quando se mudarem para uma nova área de plantio. Propriedades maiores também podem se beneficiar do uso da estrutura para sombreamento como um equipamento de apoio junto à lavoura, onde as hortaliças são mantidas sombreadas até o transporte à casa de embalagem onde são executadas operações mais complexas de beneficiamento, embalagem e armazenamento.

O uso destes equipamentos propicia os seguintes benefícios:

1) Preserva a qualidade da hortaliça colhida, por meio da redução dos estresses abióticos (calor, deposição de orvalho, chuva e danos físicos) durante a colheita e beneficiamento, e consequentemente, aumenta a sua durabilidade e o tempo disponível para a sua comercialização.

2) Preserva a saúde do trabalhador rural através da redução do tempo de exposição ao sol e dos problemas osteo-musculares devidos ao carregamento de cargas pesadas e/ou distribuídas assimetricamente e devidos a estresses na coluna, nos membros superiores e nos joelhos causados por operações repetitivas e/ou posturas inadequadas.

3) Aumenta o rendimento do trabalho de colheita e beneficiamento de hortaliças através da eliminação de etapas repetitivas, redução do cansaço causado pela sobrecarga do sistema músculo-esquelético, redução do desconforto térmico e pela possibilidade de execução do beneficiamento das hortaliças sob condições de chuva.

Vale lembrar que, enquanto os benefícios dos equipamentos sobre o rendimento do trabalho e sobre a saúde do trabalhador são percebidos durante a realização do trabalho na propriedade rural, parte dos benefícios para as hortaliças somente é percebida nos elos seguintes da cadeia, quais sejam durante a comercialização e consumo. Isto implica que a utilização dos equipamentos propicia benefícios para além da propriedade rural, o que por sua vez aponta para uma possível parceria entre os produtores rurais e seus clientes para a implantação dos equipamentos.

\section{Estágio atual de utilização da tecnologia}

Os equipamentos foram validados em quatorze propriedades do Distrito Federal e entorno com índices de adoção de $50 \%$ na primeira fase (somente a UMS) e de $87 \%$ na segunda fase (um, dois ou todos os equipamentos, a depender da necessidade do produtor). Atualmente está em uso em nove daquelas propriedades, sendo que uma das propriedades que adotou a UMS na primeira fase já substitui-a por uma cobertura de alvenaria.

A Embrapa não comercializa os equipamentos mas disponibiliza todas as informações necessárias para sua construção por marcenarias e serralherias de pequeno porte em publicações impressas e eletrônicas (Lana, 2014a, 2014b; Lana \& Batista, 2014; Lana et al., 2014). Deste modo, o produtor rural interessado pode construir seus próprios equipamentos e se necessário efetuar pequenas mudanças que os tornem mais adequados a suas necessidades.

\section{AGRADECIMENTOS}

A realização deste trabalho foi possível graças à participação ativa e soluções criativas apresentadas pelos funcionários da Embrapa Hortaliças Wilson dos Santos Ramos, Antônio Mourão de Araújo, João Batista Gomes, Raimundo José de Souza e Silva, Antônio Selmo Nunes Machado, José Alves de Moura e Valdir José Radel (In memoriam).

\section{REFERÊNCIAS}

ALMEIDA, GA; SILVA, T. (coord.). 2008. Avaliação de perdas na cadeia comercial de banana nanica, banana prata e tomate longa vida. Belo Horizonte: CEASAMINAS, FAEMG, SEBRAE-MG. 50p.

AMORIM, L; MARTINS, MC; LOURENCO, SA; GUTIERREZ, ASD; ABREU, FM; GONCALVES, FP. 2008. Stone fruit injuries and damage at the wholesale market of São Paulo, Brazil. Postharvest Biology and Technology. 47: 353-357.

BARON, S; ESTILL, CF; STEEGE, A; LALICH, N. 2001. Simple solutions: ergonomic for farm workers. Cincinnati: United States Department of Health and Human ServicesPublic Health Service, Centers for Disease Control and Prevention-National Institute for Occupational Safety and Health. 46 p. Disponível em: <http:/www.cdc.gov/niosh/ docs/2001-111/pdfs/2001-111.pdf. $>$ Acessado em 01 set. 2014.

BRASIL. 2014. Doenças Relacionadas ao Trabalho - Manual de Procedimentos para os Serviços de Saúde. 2001. Brasília: Ministério da Saúde do Brasil, Organização Pan-Americana da Saúde no Brasil. 580 p. Disponível em <http://bvsms.saude.gov. br/bvs/publicacoes/doencas_relacionadas trabalho1.pdf $>$ Acessado em 01 set. 2014.

COSTA, FG; CAIXETA FILHO, JV. 1996. Análise das perdas na comercialização de tomate: um 
estudo de caso. Informações Econômicas 26: 9-24.

FAO. 2011. Global Food Losses and Food Waste - extent, causes and prevention. Rome: FAO. $38 \mathrm{p}$.

FAO. 2014. Food wastage footprint-full-cost accounting - Final Report. Rome: FAO. 98p.

FARINA, EMMQ. 2002. Consolidation, Multinationalisation, and Competition in Brazil: Impacts on Horticulture and Dairy Products Systems. Development Policy Review 20: 441-457.

HLPE, 2014. Food losses and waste in the context of sustainable food systems. A report by the high level panel of experts on food security and nutrition of the committee on world food security. Rome: HLPE-FAO. $116 \mathrm{p}$.

LANA, MM; ANDRADE, MO; BANCI, CA. 2010. Proposição de um método para melhoria do manuseio pós-colheita de pimentão baseado no Mapeamento de Processos e Falhas e na Árvore da Realidade Atual. Brasília: Embrapa Hortaliças. 36 p. (Embrapa Hortaliças. Documentos, 130). Disponível em: <http://ainfo.cnptia.embrapa.br/digital/ bitstream/CNPH-2010/36532/1/doc-130.pdf> Acessado em 01 set. 2014.

LANA, MM. 2010. Diagnóstico do manuseio pós-colheita de couve-flor e repolho em uma cooperativa de produtores de hortaliças de Planaltina-DF. Brasília: Embrapa Hortaliças. 44 p. (Embrapa Hortaliças. Documentos, 131). Disponível em: <http://ainfo.cnptia.embrapa. br/digital/bitstream/item/102930/1/doc-131. pdf $>$ Acessado em 01 set. 2014.

LANA, MM. 2014a. Hora da colheita: hora de cuidar do seu produto e de você: casa de embalagem de lona. Brasília: Embrapa Hortaliças. 8 p. (Embrapa Hortaliças. Comunicado técnico, 100). Disponível em: http://ainfo.cnptia.embrapa.br/digital/ bitstream/item/111172/1/COT-100-X.pdf Acessado em 01 dez 2014.

LANA, MM. 2014b. Hora da colheita: hora de cuidar do seu produto e de você: mesas para seleção de hortaliças. Brasília-DF: Embrapa Hortaliças, 2014. 12p. (Embrapa Hortaliças. Comunicado técnico, 98). Disponível em: $<$ http://ainfo.cnptia.embrapa. $\mathrm{br} /$ digital/bitstream/item/101840/1/cot-98. pdf> Acessado em 01 set. 2014.

LANA, MM; BANCI, CA; BATISTA, VR. 2014. Hora da colheita: hora de cuidar do seu produto e de você. Unidade móvel para sombreamento de hortaliças após a colheita. - 2. ed. atual. Brasília: Embrapa Hortaliças. 8 p. (Embrapa Hortaliças. Comunicado Técnico, 90). Disponível em: <http://ainfo.cnptia. embrapa.br/digital/bitstream/item/103622/1/ COT-90-2ed-.pdf> Acessado em 03 out. 2014.

LANA, MM; BATISTA, VR. 2014. Hora da colheita: hora de cuidar do seu produto e de você - carrinho para transporte de hortaliças durante a colheita e comercialização. Brasília, DF: Embrapa. 12 p. (Embrapa Hortaliças. Comunicado técnico, 99). Disponível em: $<$ http://ainfo.cnptia.embrapa.br/digital/ bitstream/item/108845/1/EMBRAPA-COT99-light.pdf $>$ Acessado em 01 set. 2014.

LANA, MM; PUERTA, R. 2011. Diagnóstico do manuseio pós-colheita de pepino e de abobrinha em uma cooperativa de produtores de hortaliças de Planaltina-DF. Brasília: Embrapa Hortaliças. 53 p. il. (Embrapa Hortaliças. Documentos, 132). Disponível em: <file://CC:/Users/m295914/Downloads/doc132\%20(2).pdf> Acessado em 01 set. 2014.

REZENDE, JB. (coord). 1992. Avaliação das perdas de produtos agrícolas em MG. Belo Horizonte: FUNDAÇÃO JOÃO PINHEIRO. 122p.

SAASP-SECRETARIA DE AGRICULTURA E ABASTECIMENTO DE SÃO PAULO. 1995. Projeto de Avaliação de perdas pós-colheita de produtos hortigranjeiros no estado de São Paulo - pré-teste de avaliação metodológica (produto: tomate), São Paulo: SAASP. 69p.

TSUNECHIRO, A; UENO, LH; PONTARELLI, CTG. 1994. Avaliação econômica das perdas de hortaliças e frutas no mercado varejista da cidade de São Paulo. Agricultura em São Paulo 41: 1-15.

VILELA, NJ; LANA, MM; NASCIMENTO, E.D; MAKISHIMA, N. 2003. Perdas na comercialização de hortaliças em uma rede varejista do Distrito Federal. Cadernos de Ciência e Tecnologia 20: 521-541.

WRAP, 2008. The food we waste - Food waste report v2. London: Waste \& Resources Action Programm. 237 p.

ZAMBOM, FRA; PELUSO, AC; OLIVEIRA, LS; SOKULSKI, MVG; CUNHA, MJS. 1991. Conservação pós-colheita de hortaliças - diagnóstico dos níveis de perda na comercialização de tomate (Lycopersicum esculentum), couve-flor (Brassica oleraceae var. botrytis) e morango (Fragaria spp.) em Curitiba-PR. SOB/Informa 9/10: 35-36. 